NBER WORKING PAPER SERIES

FX COUNTERPARTY RISK AND TRADING ACTIVITY IN CURRENCY FORWARD AND FUTURES MARKETS

Richard M. Levich

Working Paper 18256

http://www.nber.org/papers/w18256

\author{
NATIONAL BUREAU OF ECONOMIC RESEARCH \\ 1050 Massachusetts Avenue \\ Cambridge, MA 02138 \\ July 2012
}

The author gratefully acknowledges financial support from the CME Group Foundation. The views expressed herein are those of the author and do not necessarily reflect the views of the National Bureau of Economic Research.

NBER working papers are circulated for discussion and comment purposes. They have not been peerreviewed or been subject to the review by the NBER Board of Directors that accompanies official NBER publications.

(C) 2012 by Richard M. Levich. All rights reserved. Short sections of text, not to exceed two paragraphs, may be quoted without explicit permission provided that full credit, including $\bigcirc$ notice, is given to the source. 
FX Counterparty Risk and Trading Activity in Currency Forward and Futures Markets

Richard M. Levich

NBER Working Paper No. 18256

July 2012

JEL No. F31,G15

\begin{abstract}
$\underline{\text { ABSTRACT }}$
The Global Financial Crisis initiated a period of market turbulence and increased counterparty risk for financial institutions. Even though the Dodd-Frank Act is likely to exempt interbank foreign exchange trading from a central counterparty mandate, market participants have the option to trade currency futures on existing futures markets which standardize counterparty risks. Evidence for the period 2005-11 indicates that the market share of currency futures trading has grown relative to the pre-crisis period. This shift may be the result of a perceived increase in counterparty risk among banks, as well as changes in relative trading costs or changes in other institutional factors.
\end{abstract}

Richard M. Levich

Stern School of Business

New York University

44 West 4th Street

New York, NY 10012

and NBER

RLEVICH@STERN.NYU.EDU 


\section{FX Counterparty Risk and Trading Activity in \\ Currency Forward and Futures Markets}

\section{Introduction}

The Global Financial Crisis initiated a period of turbulence the effects of which are still impacting financial markets. In some respects, the foreign exchange (FX) market performed well during the crisis. Trading volume held up throughout the crisis and continues to be robust. The CLS Bank, a relatively new intermediary for settling a substantial fraction of interbank FX transactions worked as planned, eliminating delivery risk for counterparties using the CLS system. ${ }^{1}$ However, in other respects the FX market was like a barometer for gauging market disruption. After the first signs of a developing crisis in summer 2007, deviations from Covered Interest Parity, the arbitrage condition that links the forward premium on currency to the shortterm offshore interest differential between a pair of currencies, ballooned from under 10 basis points to 50 and then several hundred basis points after the Lehman Brothers bankruptcy in September 2008. Around the same time, the TED spread (i.e. the spread between short-term U.S. Treasuries and short-term Eurodollar bank rates) experienced a similar pattern where the spread moved sharply upward in the summer of 2007, and then shot up to unparalleled levels after the Lehman bankruptcy. While policy changes and the process of normalization of market conditions have had the beneficial impact of reducing CIP deviations and the TED spread considerably, both measures are still substantially greater than in the pre-crisis period. And both measures are yet two more indicators of a new normal where heightened risk and risk aversion

\footnotetext{
${ }^{1}$ CLS Bank estimates that they provided settlement risk elimination services for $68 \%$ of the global foreign exchange market in April 2010 for the 17 currencies that are CLS eligible.
} 
seem to be driving a larger wedge between the traditional linkages in international financial markets.

In this paper, our interest is in exploring some of the implications that follow based on the perception that counterparty risk has grown among many traditional FX market participants. Of special interest here, the Dodd-Frank Act (2010) mandated that swap transactions must be traded and cleared through a centralized counterparty (CCP). Despite the critical importance of foreign exchange and the enormous volume of daily interbank FX trading, in April 2011 the U.S. Treasury proposed that FX swaps and forward contracts be exempted from the CCP mandate. ${ }^{2}$

Whether or not the U.S. Treasury proposal is adopted, market participants have the alternative to substitute the use of currency futures contracts traded and cleared through a CCP in place of currency forward contracts traded and settled through the interbank market. The general hypothesis we wish to examine is whether these developments (i.e. preservation of the status quo in trading and settling arrangements for FX swaps and forwards; and rising idiosyncratic risks among various important financial institutions) have helped induce FX market participants to migrate trading activity toward centralized trading and clearing organizations. As currency market participants assess their risks of dealing in the FX market, counterparty risks may be greater or more difficult to gauge in the current environment, inducing a preference for the transparency and reliability afforded by a CCP.

Because data on interbank market trading is more limited than data on futures market activity, our statistical methodology is somewhat limited. However, based on the data that are

\footnotetext{
${ }^{2}$ In the 2010 survey, FX swaps and outright forwards accounted for $47 \%$ and $13 \%$ respectively of the nearly $\$ 4$ trillion daily global turnover volume. However, the U.S. Treasury (2011, p. 7) reaffirmed that FX options, currency swaps, and non-deliverable forwards would not be exempted from the Commodity Exchange Act's definition of a swap. In other words, these contracts would still be subject to the CCP mandate in the Dodd-Frank Act.
} 
available, the data suggest that since the onset of the Global Financial Crisis the volume of trading in currency futures has grown and gained market share while the market share that can be attributed to interbank currency forward contracts has declined. Possible explanations for the shift toward currency futures include an increase in bank counterparty risks, especially at the onset of the European sovereign debt crisis in late 2009. However other possible explanations such as a relative increase in interbank trading costs or other institutional changes need to be considered.

In the next section, we review some metrics that summarize the impact of the crisis on international capital mobility. We then outline the basic architecture for interbank currency trading and highlight the important but limited role played by the CLS Bank in reducing delivery risk for interbank currency transactions. In Section IV, we describe our data on currency forward and futures market trading activity, and then present our analysis of that data in Section V. A summary of the results with policy implications and suggestions for follow-up research are in the final section.

\section{Some Metrics of the Global Financial Crisis}

The ongoing history of the Global Financial Crisis is well-documented and numerous studies have analyzed its origins. ${ }^{3}$ For our purposes, however, the Covered Interest Parity (CIP) relationship can be taken as nearly a sufficient statistic for the trading and operational efficiency of the foreign exchange market. ${ }^{4}$ The gist of CIP is that arbitrage activity will drive the oneperiod interest differential on a pair of currencies, $i(\$)-i(£)$, toward equality with the forward currency premium, (F-S)/S, when the exchange rates are expressed in units of $\$ / £$. In a perfect

\footnotetext{
${ }^{3}$ See Lo (2012) for a summary and review of 21 such volumes. See Acharya and Richardson (2009, Chapter 1) for a summary of events through late 2008.

${ }^{4}$ Exchange rate economists use covered interest parity as a measure of perfect capital mobility.
} 
market with transactions costs at zero and no counterparty or default risk, arbitrageurs would insure that deviations from CIP are zero. While meaningful deviations from CIP were observed in the first half of the twentieth century, once the offshore markets (then referred to as "Euromarkets") developed in the 1960s, numerous economic studies confirmed that for the major currencies trading in liquid markets, CIP deviations were very small, and almost always smaller than the cost of engaging in arbitrage. ${ }^{5}$

Exhibit 1 shows CIP deviations based on the 3-month maturity for the Euro versus the US Dollar from January 1, 2000 until April 30, 2012. ${ }^{6}$ The period through July 2007 appears tranquil with essentially all deviations bounded within 25 basis points of parity and upwards of 95\% of all deviations bounded within 10 basis points of parity. This period strongly conveys the notion of a highly liquid capital market with virtually perfect capital mobility between short-term EUR and USD instruments.

The graph and the message change in the summer of 2007 when two hedge funds operated by Bear Stearns suspended redemptions and BNP-Paribas announced that they were unable to value three hedge funds. More events followed into 2008 as Northern Rock, one of the top mortgage banks in the United Kingdom, was nationalized and Bearn Stearns collapsed and was sold to JP Morgan Chase. In the initial phase of this pre-Lehman crisis period, deviations from CIP jumped to roughly 40 basis points, then recovered, and after the Bear Stearns collapse returned to the 40-50 basis point range through the summer of 2008.

Once Lehman Brothers failed on September 15, 2008, deviations from CIP in the most active currency pair in the most active financial market in the world spiked to over 200 basis

\footnotetext{
${ }^{5}$ See Levich (2012) for a survey of the literature on covered interest parity including empirical evidence from the 1960s through the recent Global Financial Crisis.

${ }^{6}$ This section is based on the discussion in Levich (2012).
} 
points and for the most part remained above 100 basis points for the next three months. CIP deviations subsided to the 25-50 basis point range by spring 2009, and continued in that range for another two years. However, deviations again surged in August 2011 exceeding 100 basis points throughout November and December 2011 and then retreated to the 50 basis point range in spring 2012. The data make clear that CIP deviations have been, and are now in a far higher range compared to the tranquil period of near perfect capital mobility in the first few years of the millennium. $^{7}$

Several authors have studied what factors led to the sharp increase in CIP deviations at the start of the crisis, and the rapid decline in CIP deviations in the spring of 2009. According to Baba and Packer (2009) and corroborated by Coffey et al. (2009), the combination of funding shortages in US financial markets as well as a heightened sense of counterparty risk even among large banks active in the foreign exchange market led to a deterioration in liquidity and observed deviations from covered interest parity in the USD-EUR pair. ${ }^{8}$ Both of these studies find that prior to the Lehman Brothers bankruptcy, capital constraints and liquidity risk proxies explain much of the observed deviations from CIP. After the Lehman collapse, Coffey et al. (2009) find that counterparty risk and credit risk proxies become significant variables explaining CIP deviations.

The economic implications of these deviations from CIP were critical. European banks that might normally borrow USD from US banks were effectively shut out due to the crisis and

\footnotetext{
${ }^{7}$ Graphs of other exchange rates reveal a similar pattern of small CIP deviations during the tranquil period up until the summer of 2007, followed by a period of increasing turbulence and larger CIP deviations, and then a large spike in deviations after the Lehman Brothers bankruptcy. In most cases, CIP deviations are now generally larger than at the start of the millennium.

${ }^{8}$ Griffoli and Ranaldo (2011) analyze CIP deviations using high frequency data on 5 currency pairs including the EUR-CHF, a non-dollar pair. The authors conclude that most CIP deviations can be explained by funding liquidity constraints in USD, and only a small part due to the risk of default by the forward counterparty. Hence, based on this dataset, the possibility of risk was not a major factor in limiting arbitrage and opening up CIP deviations.
} 
heightened concerns about counterparty risks, banks' desire to retain adequate risk capital, and the declining economic climate. Europeans could create USD synthetically by borrowing EUR and completing an FX swap, but this raised their costs by the excess of the deviation from CIP.

In the spring of 2009, the U.S. Federal Reserve along with other central banks opened up substantial official swap facilities. With these official swaps, the supply of USD offshore increased and non-U.S. banks could access USD through their home central bank rather than through their traditional U.S. commercial bank counterparties (who were subject to heightened default risk). Coffey et al. (2009) show that the successive rounds of official swap facility lines opened in the spring 2009 played a significant role in bringing down CIP deviations, and in that sense, helped to restore greater international capital mobility.

Despite these policy initiatives, Exhibit 1 suggests that deviations from covered interest parity are experiencing a new normal, with deviations in the range of 25-50 basis points for the EUR-USD pair rather than in the range of 10-25 basis points which had been observed a decade previously.

The TED spread shown in Exhibit 2a shows a similar pattern to CIP deviations. For many years extending into the new millennium, the TED spread was typically in the 10-25 basis point range. The spread began climbing in 2006-7 but remained well under 100 basis points until spiking in the summer of 2007, and then hitting unprecedented levels in the fall of 2008. The TED spread has declined considerably since 2008 as shown in Exhibit 2b, but it remains higher than a decade earlier.

Credit default swap (CDS) rates may offer the most direct evidence of increased risk at major banks. Exhibit 3 shows the monthly average for 10 international banks of their 5-year CDS 
rates from January 2005 - April 2012. Similar to our earlier charts, CDS rates were small (under 20 basis points) and fairly tranquil until summer 2007 when the average rate doubled, and then doubled again in spring 2008 to over 100 basis points. In September 2008, average rates jumped to over 150 basis points before peaking to over 200 basis points in March 2009 when equity prices hit their lows. CDS rates subsided through 2009 and remained fairly steady through 2010. With the ongoing European sovereign debt crisis and concerns over the levels of bank capital, average CDS rates resumed their climb in the fall of 2011 to over 200 basis points before tapering off in spring 2012. The similarity in the patterns of CDS rates and CIP deviations is apparent.

In sum, data on deviations from CIP, the TED spread, and particularly CDS rates suggest that credit risk and counterparty default risk have increased for large international financial institutions relative to their pre-crisis levels.

\section{Simple Mechanics of Interbank Foreign Exchange Trading and the Role of the CLS Bank $^{9}$}

While the foreign exchange market has evolved considerably over the last 20 years, some important features of the traditional or classic market remain in place. ${ }^{10}$ The foreign exchange market has always been and remains a geographically dispersed, broker-dealer market. The interbank FX market is not housed in any city or trading floor, but instead is comprised of individuals known as dealers, traders or market makers who work for large banks and financial institutions. FX dealers communicate and trade with one another either through brokers who assemble price quotations from numerous other market makers and match counterparties, or via direct dealing whereby a dealer from Bank A contacts a dealer from Bank B, either via cable,

\footnotetext{
9 This section is adapted from Pojarliev and Levich (2012).

${ }^{10}$ See King, Osler, and Rime (2011) for a more detailed discussion of foreign exchange market structure and its evolution.
} 
telex, telephone, or web-based network depending on the available technology. Using a voice broker, or for the last 25 years or so an electronic broking system, allows the bank dealers to remain anonymous until the trade is agreed upon and delivery and settlement information is exchanged. Direct dealing on the other hand puts bank dealers A and B in direct contact with one another, which eliminates the broker's fee but exposes the dealers to the risk of revealing information about their inventory positions or their view on market conditions.

The corporate or retail sector of the FX market represents another market segment that is serviced by the core interbank market. Traditionally, corporate FX transactions were executed based on communication between a corporate treasury manager and a bank corporate FX trading desk. Corporate treasurers were free to shop amongst their relationship banks, but shopping could be time consuming and costly (in terms of lost opportunities). Since 2000, newly introduced web-based platforms have given corporations the option to conduct their FX trades in a reverse-auction setting, whereby banks bid for the corporate trade. ${ }^{11}$ For equity investors, banks and custodians have typically bundled the FX trade into the execution of a foreign securities transaction. For example, when a U.S. pension fund manager buys or sells shares of Nestle on the Swiss market, the broker or custodian handling the equity trade would also handle the attendant currency transaction. ${ }^{12}$ The development of prime brokerage agreements has greatly facilitated the entry of many smaller banks, mutual funds, hedge funds, and specialized money managers into the foreign exchange market. While these entities would have appeared as retail clients in the past, they now trade on far more favorable essentially interbank terms.

\footnotetext{
${ }^{11}$ Companies offering this service include Currenex, founded in 2000 and acquired by State Street Bank in 2007, FX Alliance, and FX Connect.

${ }^{12}$ Linking the equity and FX pieces of the transaction could be desired to take account of timing differences in clearing and settlement between equity and FX. Litigation is now pending between several U.S. pension funds and custodian banks regarding alleged irregularities in FX trades that were bundled with equity transactions. See Dash (2009) and Dash and Lattman (2011).
} 
The structure of FX trading has some important differences compared to equity and futures market trading, especially those trades executed on an organized exchange. As noted above, the foreign exchange market is a geographically dispersed market with no centralized trading floor. Trading in the major currency pairs (EUR/USD, USD/JPY, and GBP/USD) is essentially continuous throughout the 24-hour day, although trading is more active as the major trading centers (i.e. Tokyo, followed by Europe, and then the United States) have their sequential normal business hours. Unlike most equity and futures markets, there is no national regulatory authority that oversees interbank FX trading. ${ }^{13}$ Also, unlike equity and futures trades that are funneled through an exchange, there is no public record of the price and volume of interbank FX transactions as they occur through the day. The terms of a trade between Bank A and Bank B or between Bank A and their client remains private information. There is no ticker tape that reports actual transaction prices of FX trades. Prices that are circulated via Bloomberg and other web based systems are usually indicative meaning that actual transaction prices could be different. ${ }^{14}$

The bilateral nature of FX transactions (i.e. Bank A trades with Bank B, or Bank A trades with their client) suggests the heterogeneous nature of prices and trading risks that accompany seemingly similar trades between the same pair of currencies. Because the FX market is not centralized and many visible quotations are not necessarily indicative of future transaction prices, there can be some heterogeneity in transaction prices between Banks A and B versus prices between Banks C and D at any instant of time. Perhaps more important, because banks in

\footnotetext{
${ }^{13}$ There are industry groups in many of the major trading centers who work to develop guidelines for FX trading and best practices for operational risk management. The web site of New York's Foreign Exchange Committee (see http://www.newyorkfed.org/fxc/links.html ) provides further information and links to other sites.

${ }^{14}$ Some studies suggest that it is the opaque nature of the foreign exchange market that enables market-makers to profit. Banks may take an incoming order to buy or sell at a small deviation from market prices, and then cover their position quickly without much impact on prices. See Yao (1997) and Lyons (2001). Hafeez and Brehon (2010) suggest that some corporate clients and equity investors are somewhat price insensitive, as they view foreign exchange as a cost rather than their mainline business, which further supports the prospects for profitable marketmaking.
} 
this example each have a distinct credit risk, the risk profiles of the two trades (i.e. a EUR/USD trade involving Banks A and B, versus another EUR/USD trade involving Banks C and D) could also differ. By comparison, the ultimate counterparties to all trades on organized futures and option exchanges as well as trades on US equity exchanges are anonymous to one another. This system functions because for futures and options, the exchange clearinghouse acts as the legal counterparty to all trades, and all transactions in US equity exchanges pass through the Depositary Trust and Clearing Corporation (DTCC) system which at the end of day $\mathrm{T}+1$ inserts the National Security Clearing Corporation (NSCC) as the counterparty to all trades. ${ }^{15}$

As an example of a type of trading risk that impacts foreign exchange trading, consider a transaction whereby Bank A sells JPY 80 million to Bank B in exchange for USD 1 million for delivery on day T. Bank A would deliver its JPY to Bank B's account in Tokyo on the morning of day T. The problem is that when it is 10:00 a.m. in Tokyo, the time in New York is usually 9:00 p.m. on the evening of day $T-1$, a time when New York banks are closed for business. If Bank B were unable to deliver its USD in New York 10-12 hours later (because of bankruptcy or some other reason), then Bank A would have suffered a total loss by paying out its leg of the transaction (the JPY) in Tokyo while not receiving the other leg of the transaction (the USD) in New York.

While this example could seem like a remote possibility, or simply extremely bad luck, events like this have occurred in the past. On the morning of June 26, 1974, various banks paid out millions of Deutsche Marks to the Herstatt Bank in Cologne, Germany. Latter that day, but

\footnotetext{
${ }^{15}$ See Morris and Goldstein (2009), Guide to Clearing and Settlement, for an overview of clearing and settlement in US equity markets.
} 
before it could make USD payments to its counterparties in New York, Herstatt Bank filed for bankruptcy thus leaving its counterparties with a total loss. ${ }^{16}$

The possibility of a total loss coupled with the hard reality that banking hours around the world do not sufficiently overlap led policymakers and bankers to develop a new institution. Beginning in 2002, the CLS Bank was launched to help standardize and reduce the settlement risk that affects foreign exchange transactions. In brief, the CLS Bank, an acronym for continuous linked settlement, operates a payment-versus-payment system for settling transactions. In our example, Bank A would transfer its JPY to the CLS Bank which holds them until Bank B has transferred its USD to the CLS Bank representing the matching leg of the transaction. After the CLS Bank verifies that both legs of the transaction have been paid in, then the CLS Bank pays out the USD and JPY balances. In the event that the CLS Bank does not receive one leg of the transaction, then any funds that are received are returned to the one performing counterparty. ${ }^{17}$

As this example of a busted trade demonstrates, the CLS Bank removes the possibility of Bank A transferring JPY 80 million to Tokyo and getting nothing in return. However, in the event of a busted trade where Bank A is left holding JPY 80 million, Bank A could find that it requires more than JPY 80 million to purchase USD 1 million as it originally intended. In this

\footnotetext{
${ }^{16}$ Other examples of "Herstatt” risk have been documented. Most recently, the KfW Bank in Germany had arranged for bilateral settlement of a EUR/USD transaction with Lehman Brothers for delivery on September 15, 2008. KfW delivered approximately EUR 300 million to a Lehman Brothers European bank account. However, once it declared bankruptcy, Lehman did not produce its USD leg of the transaction. See Kulish (2008).

${ }^{17}$ The U.S. Treasury (2011) pointed to a well-functioning settlement process plus the fact that FX swaps and forwards require a physical exchange of currency on fixed terms set at the outset of the contract and other factors as reasons to exempt FX swaps and forwards from the requirement in the Dodd-Frank act for a central clearinghouse for derivative securities. The U.S. Treasury proposal was offered in April 2011 and has yet to be enacted.
} 
case, Bank B's default on its leg of the original transaction will inflict a partial loss on Bank A, but not a total loss had it decided to settle bilaterally rather than by using the CLS Bank. ${ }^{18}$

To restate this result more succinctly, for interbank FX trading, the CLS Bank entirely mitigates the possibility of delivery risk but each counterparty retains the price risk element of credit risk in the event that one counterparty fails to deliver its leg of the transaction. In that event, the surviving counterparty must seek a new counterparty to complete the original deal, running the risk that the new price from the new counterparty will be inferior to the original price arranged with the original now defunct counterparty.

Thus, while the CLS Bank creates an enormous benefit for the interbank FX market, it does not completely mitigate the counterparty risk that is a feature of any bilateral transaction. Transactions at the time of the REFCO bankruptcy in October 2005 illustrate the benefits and limitations of CLS. According to Jonathan Butterfield, a CLS vice president at the time, "There were no fails with Refco. If trades were left in the system, we got payment versus payment (PVP). All participants had full oversight of their trades' status and daily net positions as the situation developed.” ${ }^{\prime 19}$ But this obscures the point that when a counterparty fails, it then becomes incumbent on the counterparties to settle in some other way. Oliver (2005) summarizes the limited task of the CLS Bank as follows: "CLS is not a clearing house, as many wrongly assume, so it does not guarantee a trade in the event of a counterparty's collapse. It does not, in fact, even guarantee settlement. What it does do is ensure that if trades are entered, one side of the transaction cannot be paid away unless there is PVP [payment versus payment], which is the simultaneous exchange of the two currencies involved in the deal.”

\footnotetext{
${ }^{18}$ The price risk associated with default could be more important for forward contracts where there is a longer period between booking the trade and delivery, and therefore more time for one counterparty to fail prior to settlement date.

${ }^{19}$ Quoted in Oliver (2005).
} 
By comparison, currency futures contracts traded on a centralized exchange all carry the identical counterparty risk of the clearinghouse that stands behind each futures contract. Thus an agent who transacts in currency futures eliminates both the delivery risk and price risk that accompany a bilateral forward FX contract in the event of default. The trade-off is that the agent accepts the cash flow risk that comes with the mark-to-market convention of futures contracts, the risk that the CCP itself might fail, and the residual risks that come from using a standardized futures contract rather than a customized currency forward contract. ${ }^{20}$ The recent bankruptcy of MF Global also brings to light the risk that brokerage firms could misappropriate customer margin account funds needed to support futures trading. While futures exchanges are likely to make brokerage firms subject to more stringent guidelines regarding investing customer funds, customer confidence in the system has been impacted. ${ }^{21}$

Overall, the institutional features of the two venues suggest that with the increase in bank counterparty risk and the imperfect mechanism in the interbank market for mitigating counterparty default risk, agents may be attracted to centralized currency futures markets as a way to reduce their exposure to these risks. At the same time, banks may be less keen to deal with, or arrange prime brokerage relationships for new or smaller currency players, leaving them to trade in futures markets. ${ }^{22}$

\footnotetext{
${ }^{20}$ A futures contract may offer an imperfect match for the amount and maturity date of a forward currency commitment.

${ }^{21}$ See Weitzman (2012).

${ }^{22}$ Assets under management in the Barclay Currency Traders Index which tracks currency hedge fund performance have grown substantially, from under $\$ 5$ billion in 2000 to nearly $\$ 30$ billion in 2011. See Pojarliev and Levich (2012).
} 


\section{Data on Currency Forward and Currency Futures Trading Activity}

Data on currency futures trading activity is readily available as these contracts are traded on regulated exchanges. We collected daily data from Bloomberg on the volume of trading for six major currency futures contracts (EUR, JPY, GBP, CAD, CHF, and AUD) traded against the USD on the Chicago Mercantile Exchange (CME) for the period June 2005 - December 2011. Data are on the aggregate volume of futures trades including the near-term contract, which is usually the most active, as well as longer maturity contracts. Each contract represents a certain number of foreign currency units which when converted at the current spot exchange rate yields the USD volume of futures contract trading. A small number of other exchanges (e.g. Osaka Securities Exchange, Tokyo Financial Exchange, among others) trade currency futures but their volumes tend to be small relative to the CME.

Data on interbank currency trading is more difficult to obtain. The Bank for International Settlements (BIS) conducts a triennial survey by selecting a representative month (April) and engaging many central banks to administer a survey of currency trading activity over the month. The last survey was administered in April 2010 involving 53 central banks and over 1,300 reporting dealers. This survey has been administered since 1989 and in conjunction with earlier less elaborate surveys provides a useful timeline for general trends in FX turnover.

In this study, we make use of separate data collected by various “FX Committees” that have developed in many of the world's major FX trading centers. These committees are quasiofficial bodies that act as an interface between bank regulators and the FX trading community and work to develop guidelines for FX trading operations. We rely on six sources including the Australian FX Committee, Canadian FX Committee, FX Joint Standing Committee (London), 
New York FX Committee, Singapore FX Market Committee, and Tokyo FX Market Committee for data starting in October 2005 until October 2011. Three committees (London, New York, and Singapore) survey trading activity twice annually (in April and October) for all the major currency pairs (EUR, JPY, GBP, CAD, CHF, and AUD) that match the futures contracts traded on the CME. Australia does not cover the GBP, CAD, and CHF until April 2007. Canada only reports CAD trading. And Tokyo only conducts the survey in April and only for 4 currencies (EUR, JPY, GBP, and AUD). We collected the data on outright forward contract trading volume for each currency pair and survey month as reported by each FX committee.

\section{Empirical Results}

\section{EUR-USD Futures and Forwards}

In this paper, we concentrate on data for the EUR-USD exchange rate which is the most actively traded currency pair in the interbank FX market, capturing $28 \%$ of all FX market turnover according to the BIS 2010 survey. The second most active pair is the USD-JPY rate which reflects $14 \%$ of all market turnover. The shares of turnover for the other four currencies GBP, AUD, CAD and CHF (against the USD) are 9\%, 6\%, 5\% and $4 \%$ respectively making a total $66 \%$ share of total FX turnover for these 6 currency pairs.

Exhibit 4 shows the daily average trading volume for EUR futures on the CME and outright forwards as reported by four FX Committees (London, New York, Singapore and Australia). ${ }^{23}$ A general upward drift in the daily volume of futures and forward trading is

\footnotetext{
${ }^{23}$ According to the BIS 2010 survey, these four locations accounted for 36.7\%, 17.9\%, 5.3\% and 3.8\% respectively (or collectively 63.7\%) of all global FX turnover. Japan which was omitted because it provides data only in April
} 
apparent, from roughly \$58 billion in October 2005 to almost \$132 billion in October 2011. A spike in interbank forward volume stands out in October 2008 immediately after the Lehman Brothers bankruptcy, and then a collapse in volume at the next survey in April 2009. Foreign exchange trading volume generally expanded significantly in the month after the Lehman bankruptcy as market participants rushed to liquidate positions, raise liquidity, and reduce exposure to foreign exchange risks. Thanks to the CLS Bank and the virtual certainty that delivery risk could be assumed away, banks gained the confidence to trade in quantity with counterparties around the world. ${ }^{24}$ However, by April 2009 the economic contraction had taken hold and the volume of both outright forwards and currency futures shrank to levels somewhat lower than their pre-crisis levels.

In the six surveys since the October 2008 spike, the upward trend in volume has resumed and noticeably at a steeper rate of increase for currency futures compared with currency forwards. Post-Lehman Brothers, the daily average volume of currency futures has expanded by 102\% from \$29.8 billion in April 2009 to $\$ 60.2$ billion in October 2011. By comparison, over the same period the daily average volume of currency forwards grew by only 25\% from $\$ 57.6$ billion to $\$ 71.8$ billion. Expressing these data in terms of market share, Exhibit 5 shows that the market share of CME currency futures has risen to somewhere in the mid-40\% range whereas prior to the crisis, the CME share was in the low 30\% range.

To probe a bit further, it would be interesting to examine whether this shift in market share is the result of an increase in the rate of growth in futures trading, or a decrease in the rate

and not October accounted for 6.2\% of all FX turnover. However, daily average trading in EUR-USD outright forwards in the April survey months was only about \$1 billion in Japan. And Canada, the final omitted country for lack of EUR-USD data accounted for only 1.2\% of FX turnover in the BIS 2010 survey. So the impact of omitting Japan and Canada in these calculations should not be material.

${ }^{24}$ See Levich (2009) for a discussion of the CLS Bank and FX trading activity over this period. 
of growth in forward market trading, or both. Unfortunately, because of the limited data on interbank trading activity, only rough answers are possible. Exhibit 6 shows the daily average of trading for CME futures on the EUR based on a 3-month moving average (right scale). The results of the 13 surveys of the interbank forward trading are superimposed (left scale). The graph makes the visual impression that CME futures volume for the EUR is growing at roughly the same rate post-crisis as it was pre-crisis. The disruption associated with the crisis itself, and the difficulty in dating the start, or end, of the crisis makes sharper comparisons problematic. For the interbank market, leaving out the spike on October 2008, the data give the impression of a shift down in volume, and possibly also a slow down in the rate of growth.

\section{Futures and Forwards on Other Currency Pairs}

We also collected data on the volume of futures trading for the five other currency pairs covered in the periodic FX Committee surveys. Exhibit 7 shows the time series behavior of average daily trading volume for AUD, GBP, CAD, JPY, and CHF currency futures as well as the EUR. The chart plots an index of the 3-month moving average of the USD-denominated value of daily trading from September 1, 2005 - December 31, 2011 with the initial observation set at 100 . Note that AUD trading volume rose in value by about 10 times over this period as expressed on the right-hand axis. Trading volume for the other five currencies rose by roughly 23 times over the period as shown on the left-hand axis.

For most currencies, trading volume declines considerably in the vicinity of the Lehman Brothers bankruptcy on September 15, 2008. The decline comes a little earlier for the CHF, GBP and CAD, and a little later for the JPY. Volume bottoms out around March 2009 (coincident with 
the lows of the U.S. equity market) and then begins to climb rapidly with the exception of the JPY where volume does not begin to advance until June 2009. Two currencies show a marked decline in trading volume toward the end of the sample. The volume of JPY futures trading declines by about $40 \%$ from April 2011, about one month after the major Japanese earthquake and tsunami, until December 2011. Starting around August 2011, just ahead of the Swiss National Bank's massive intervention resulting in what many economists label a de facto pegged rate, the volume of CHF futures trading declines by almost 60\% until December 2011.

To gauge the impact of exchange rate changes on the above results, Exhibit 8 reports the daily average number of contracts traded in 2011-Q4 compared with 2005-Q3. The volume of CHF contracts shows a decline of about $15 \%$ over this time span, whereas contract volume has grown by $60-170 \%$ for the JPY, CAD, EUR and GBP. The AUD is an outlier where the daily average number of contracts traded is 7.2 times as large in 2011-Q4 compared with 2005-Q3. Given the general depreciation of the USD against our sample currencies, the USD value of contracts traded on the CME has grown considerably more for the AUD, but also to some extent for the CAD, JPY and CHF. The USD tended to strengthen versus the GBP, so that the growth in the USD value of contracts traded is slightly less than the growth in contract volume.

Finally, Exhibit 9 provides estimates of the percentage market share of CME trading volume in the combined market of futures and forwards. As mentioned earlier, these estimates are only available for April and October when the FX Committees survey interbank market trading activity. Data for the EUR in column 1 was reviewed earlier. These data suggest that the CME's market share for EUR currency futures has risen to somewhere in the mid-40\% range whereas prior to the crisis, the CME share was in the low 30\% range. The increase for the AUD is considerably greater, with the CME's market share is in the $35-40 \%$ range now versus $20-30 \%$ 
prior to the crisis. There also appears to be growth for the CME's market share in the CAD, although the share itself appears small at only 10\%. For the other three currencies (GBP, JPY, and CHF), the CME's market share shows no clear pattern of change post- versus pre-crisis. Incorporating the annual April interbank numbers from the Tokyo survey for the JPY shows the impact (as expected) in the CME market share estimate when Tokyo's interbank forwards are included, but there is still no clear pattern of change in market share.

\section{Summary and Policy Implications}

The onset of the Global Financial Crisis and the Lehman bankruptcy were clearly watershed events that disrupted virtually all aspects of national financial markets and international financial market relationships. While the deep dislocations associated with the crisis are past, deviations from Covered Interest Parity have increased significantly relative to precrisis levels, signaling a decrease in international capital mobility. In addition, a second shock emanating from the European sovereign debt crisis and concern over the creditworthiness of banks generally have kept CDS rates high even though monetary authorities have taken steps to address the capital mobility problem.

Despite the increased awareness of risk and the desire to insulate financial institutions from future dislocations, the U.S. Treasury has recommended that FX swaps and forwards be exempt from using a central counterparty for clearing and settlement. This recommendation was based in part on the judgment that the interbank foreign exchange market already enjoys a wellfunctioning settlement process (of which the CLS Bank is one element) and that FX swaps and forwards require a physical exchange of currency on fixed terms set at the outset of the contract. 
However, FX market participants who feel that the interbank market offers too few safeguards have the alternative to use exchange-traded currency futures contracts in place of forwards. At the same time, banks may be less willing to provide financing and access to the FX market for new currency fund managers and a small but growing retail sector. While it is well known that various institutional features make futures and forward imperfect substitutes, market participants are free to evaluate all the trade-offs and migrate toward their preferred market venue.

Data collected on trading activity in currency forward and futures over a period roughly three years before and after the Lehman Brothers bankruptcy suggest that a shift toward currency futures is beginning to take place, at least among the few currencies we analyzed. The perceived upward shift in bank counterparty risk, especially at the onset of the European sovereign debt crisis in late 2009, offers one plausible explanation for the apparent increase. However other possible explanations such as a relative increase in interbank trading costs or other institutional changes need to be considered. 


\section{References}

Acharya, Viral and Matthew Richardson, (eds.) 2009. Restoring Financial Stability: How to Repair a Failed System, John Wiley, Inc.

Baba, Naohiko and Frank Packer. 2009 "Interpreting Deviations from Covered Interest Parity During the Financial Market Turmoil of 2007-08," Journal of Banking and Finance, Vol. 33, pp. 1953-62.

Coffey, Niall, Warren B. Hrung and Asani Sarkar. 2009 "Capital Constraints, Counterparty Risk, and Deviations from Covered Interest Rate Parity," Federal Reserve Bank of New York Staff Reports, no. 393 (September).

Dash, Eric. 2009. "State Street Bank Accused of Fraud by California,” New York Times, October 21.

Dash, Eric and Peter Lattman. 2011. "U.S. and New York Sue Bank of New York Mellon Over Foreign Exchange Fees,” New York Times, October 4.

Dodd-Frank Wall Street Reform and Consumer Protection Act, Public Law 111-203, §2, July 21, 2010, 124 Stat. 1386.

Griffoli, T.M. and A. Ranaldo. 2011. "Limits to arbitrage during the crisis: funding liquidity constraints and covered interest parity" Swiss National Bank, working paper. (February) http://ssrn.com/abstract=1549668

Hafeez, Bilal and Daniel Brehon. 2010. "30 Years of FX Investment Returns: dbCR and dbCR+," Exchange Rate Perspectives, Deutsche Bank, February 10.

King, Michael R., Carol Osler and Dagfinn Rime. 2011. "Foreign exchange market structure, players and evolution,” Norges Bank, working paper \#10.

Kulish, Nicholas. 2008. "Uproar Over German Bank’s Payout to Lehman,” New York Times, September 19.

Levich, R.M. 2009. "Why foreign exchange transactions did not freeze up during the global financial crisis: The role of the CLS Bank," posted at http:///www.VoxEU.org.

Levich, R.M. 2012. "Evidence on Financial Globalization and Crises: Interest Rate Parity,” in Gerard Caprio (ed.), The Encyclopedia of Financial Globalization, Elsevier Publishing Inc., forthcoming.

Lo, Andrew W. 2012. "Reading about the Financial Crisis: A Twenty-One-Book Review," Journal of Economic Literature Vol. 50, No. 1, (March): 151-78.

Lyons, Richard K. 2001. The Microstructure Approach to Exchange Rates. MIT Press, Cambridge,

MA. 
Morris Virginia B. and Stuart Z. Goldstein. 2009. Guide to Clearance \& Settlement, New York: Lightbulb Press.

Oliver, Lee. 2005. “Settlement: CLS Passes the Refco Test,” Euromoney, December.

Pojarliev, M. and R.M. Levich. 2012. Currency Management in the Post-Crash Era, CFA Institute, Charlottesville, VA. forthcoming.

United States Treasury. 2011. "Determination of Foreign Exchange Swaps and Foreign Exchange Forwards under the Commodity Exchange Act," Notice of Proposed Determination, April.

Weitzman, Hal. 2012. “MF Global Leaves Industry Scarred,” Financial Times, April 29.

Yao, Jian. 1997. Essays on Market Making in the Interbank Foreign Exchange Market, unpublished PhD thesis, New York University. 
Exhibit 1. Deviations from Covered Interest Parity for the EUR-USD, 3-month maturity

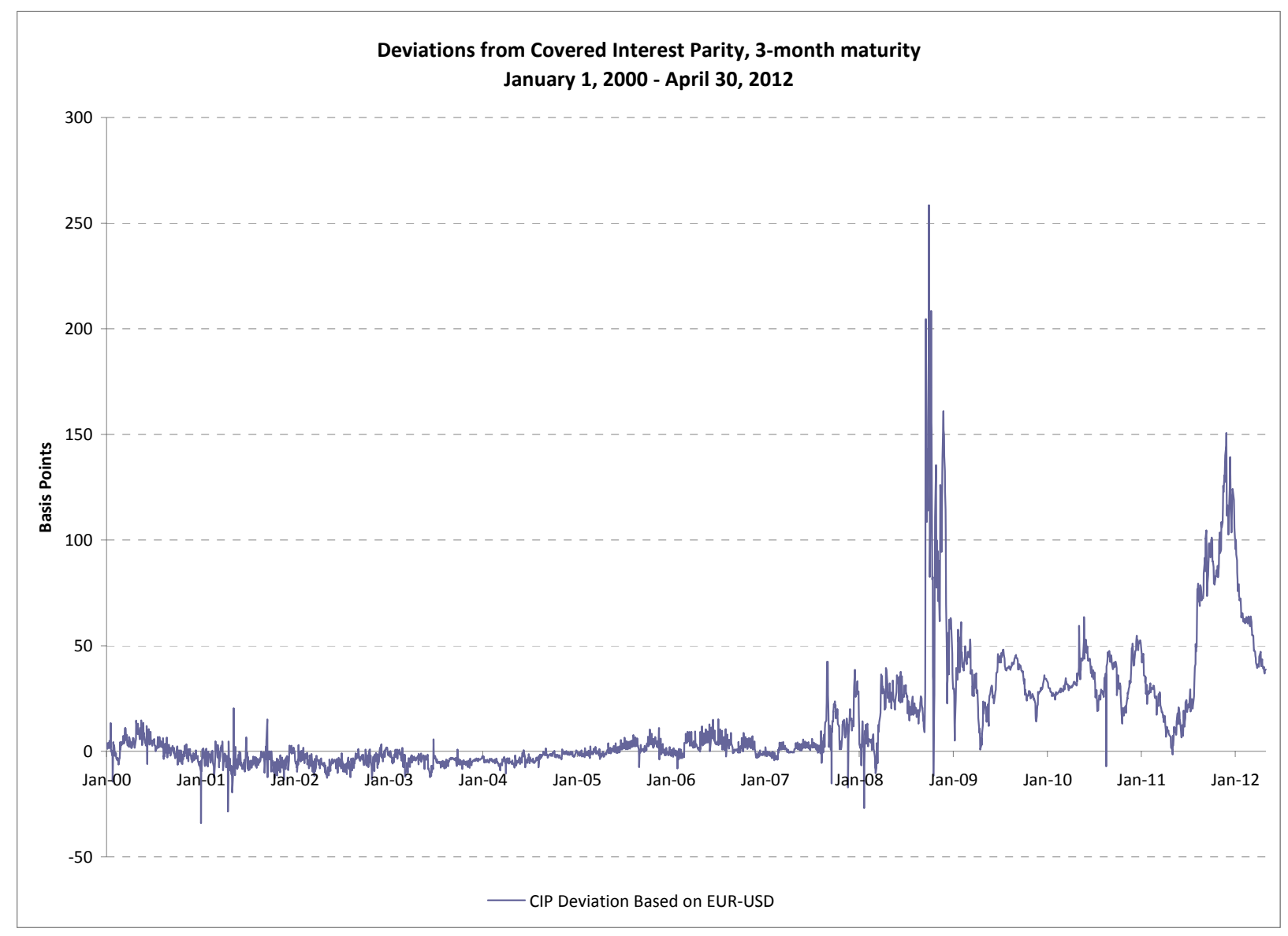

Note: Daily data on EUR/USD spot rates, 3-month forward rates, and 3-month LIBOR rates on the USD and EUR are from Bloomberg. Deviations from covered interest parity in basis points per annum calculated as [(F/S) x $(1+\mathrm{i}(\mathrm{EUR}) / 400)-(1+\mathrm{i}(\mathrm{USD}) / 400)] \mathrm{x}$ 40,000 . 
Exhibit 2a. The TED Spread Prior to the Global Financial Crisis

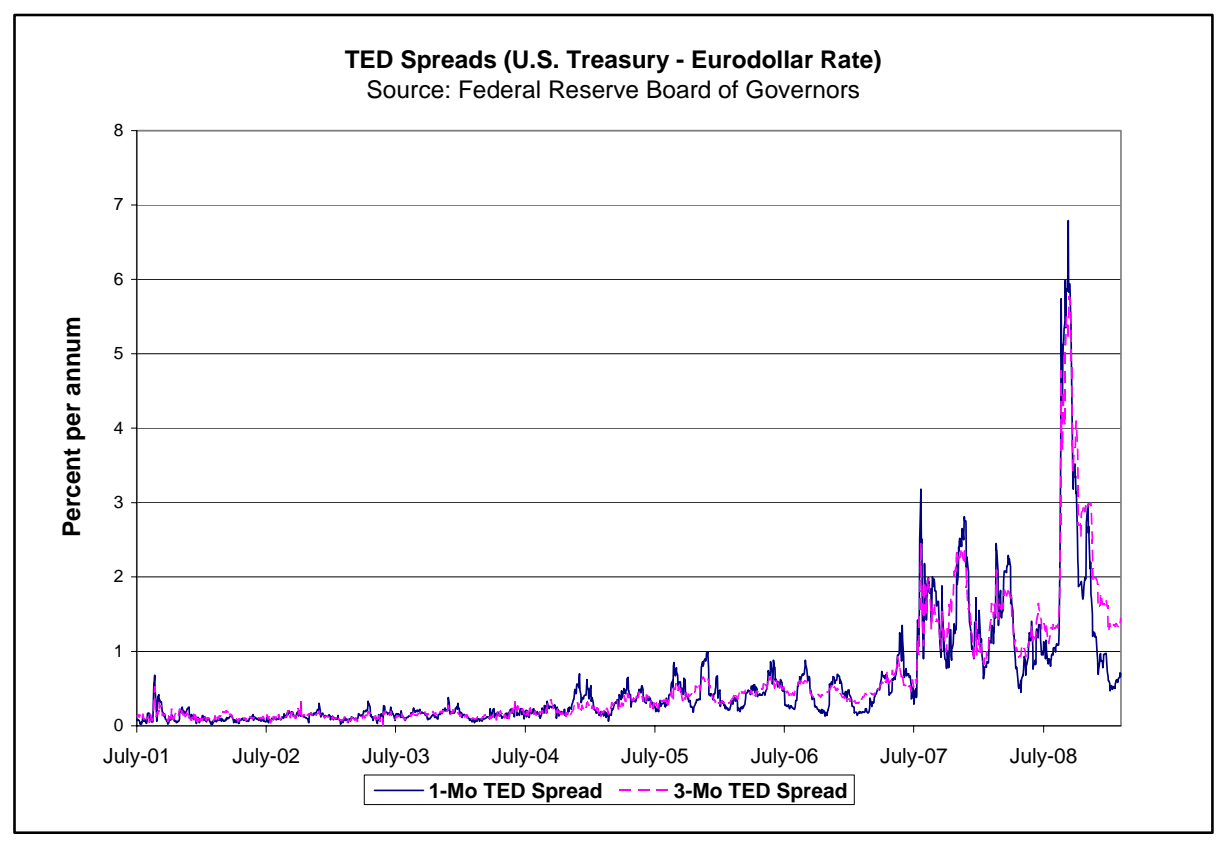

Exhibit 2b. The TED Spread During and After the Global Financial Crisis

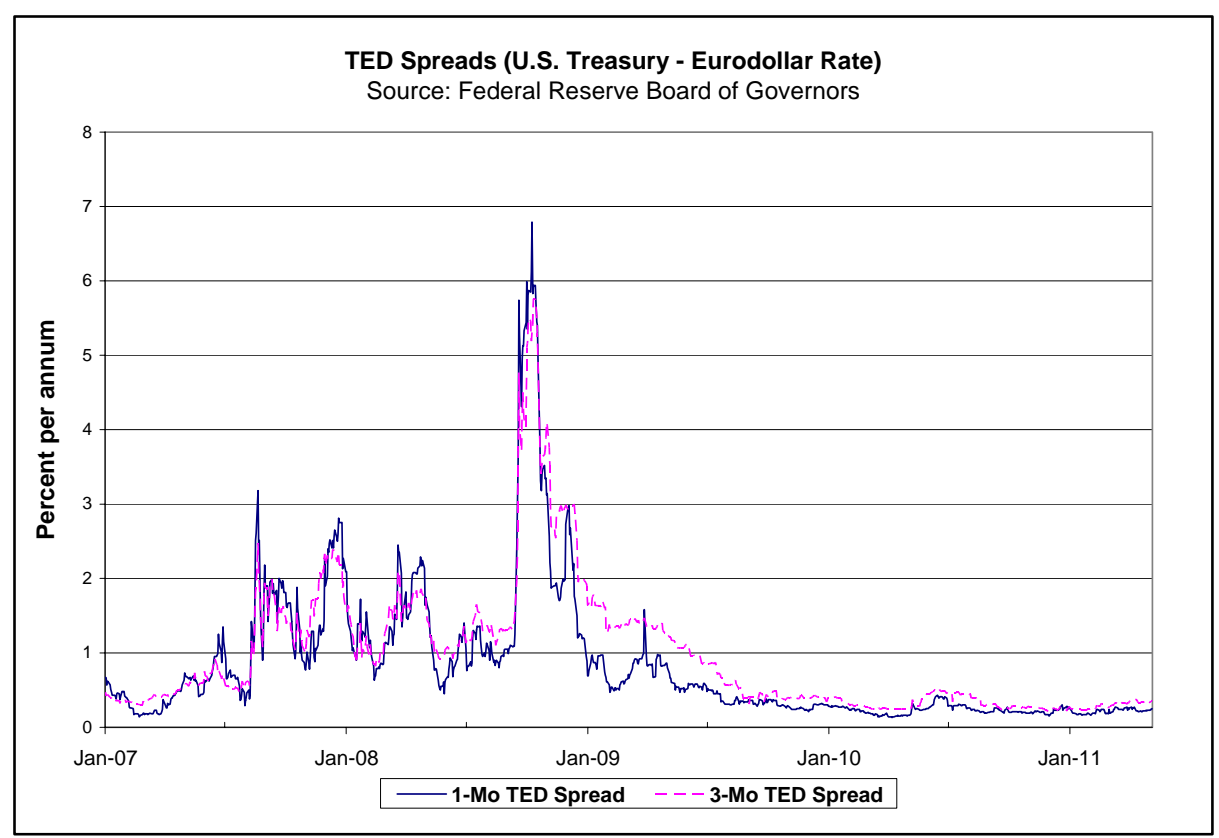


Exhibit 3. 5-Year CDS Rates: Monthly Average of 10 International Banks, January 2005 April 2012

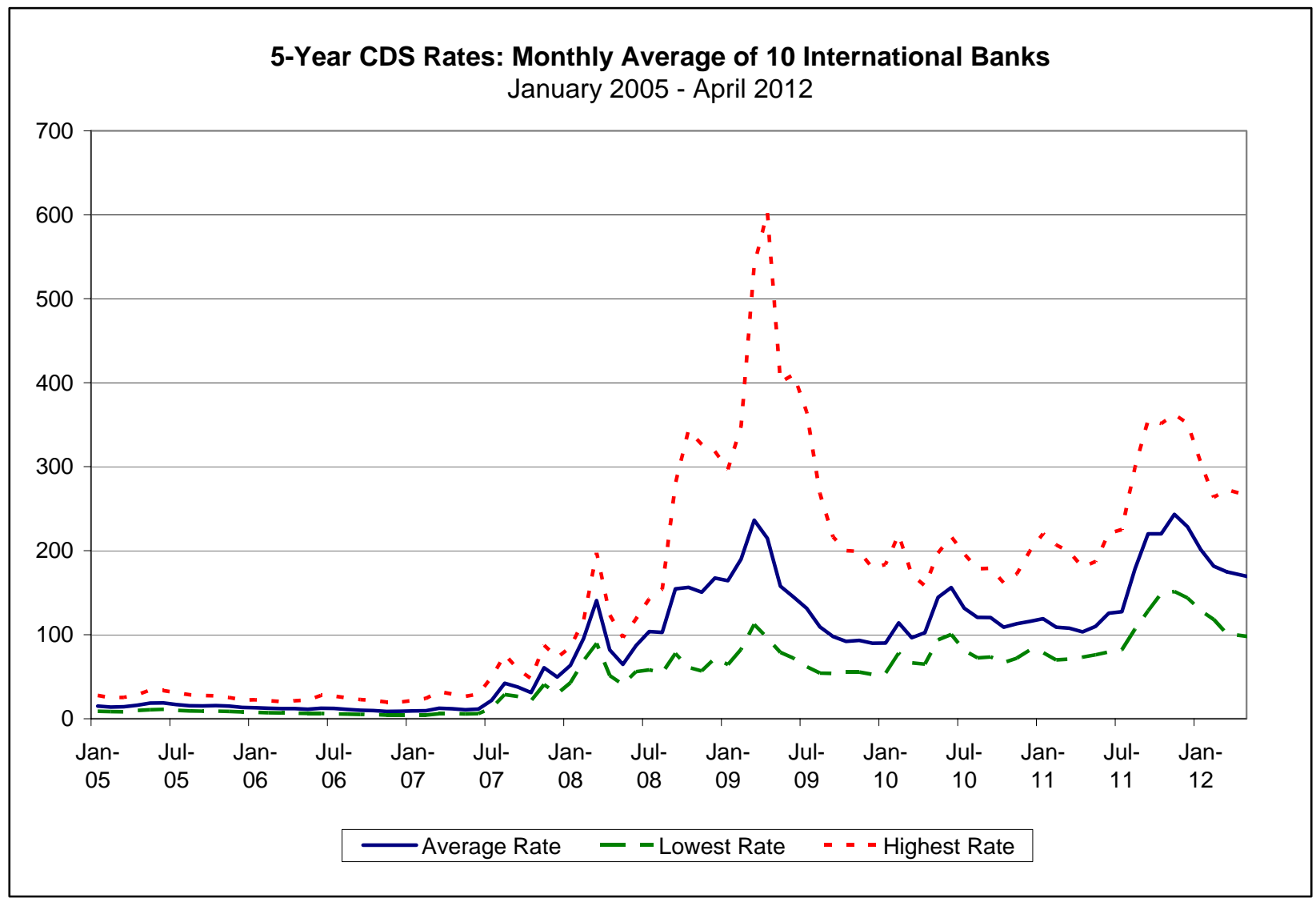

Note: The banks in the sample are BNP Paribas, Deutsche Bank, UBS, Barclays, Royal Bank of Scotland, HSBC Bank, Credit Suisse, Citibank, Goldman Sachs, and JP Morgan Chase. Data on CDS rates are from Bloomberg. 
Exhibit 4. Daily Average Trading Volume for EUR-USD Futures and Forward Contract

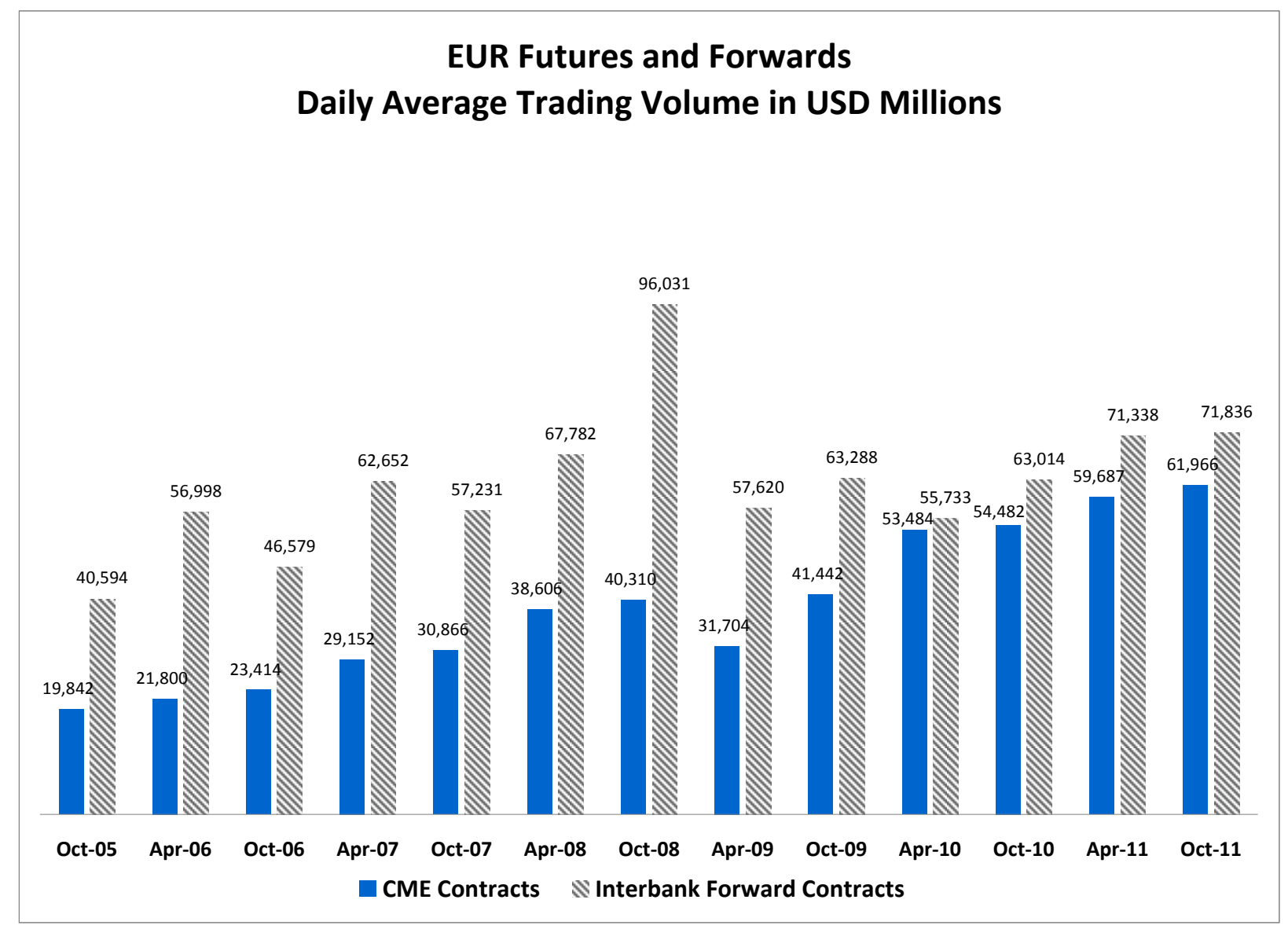

Note: Data on the aggregate volume of CME futures are from Bloomberg. Data on interbank outright forward contracts are from periodic surveys conducted by FX Committees in London, New York, Singapore, and Australia. 
Exhibit 5. CME Market Share in the Combined Market for Currency Futures and Currency Forward Contracts, EUR-USD pair only

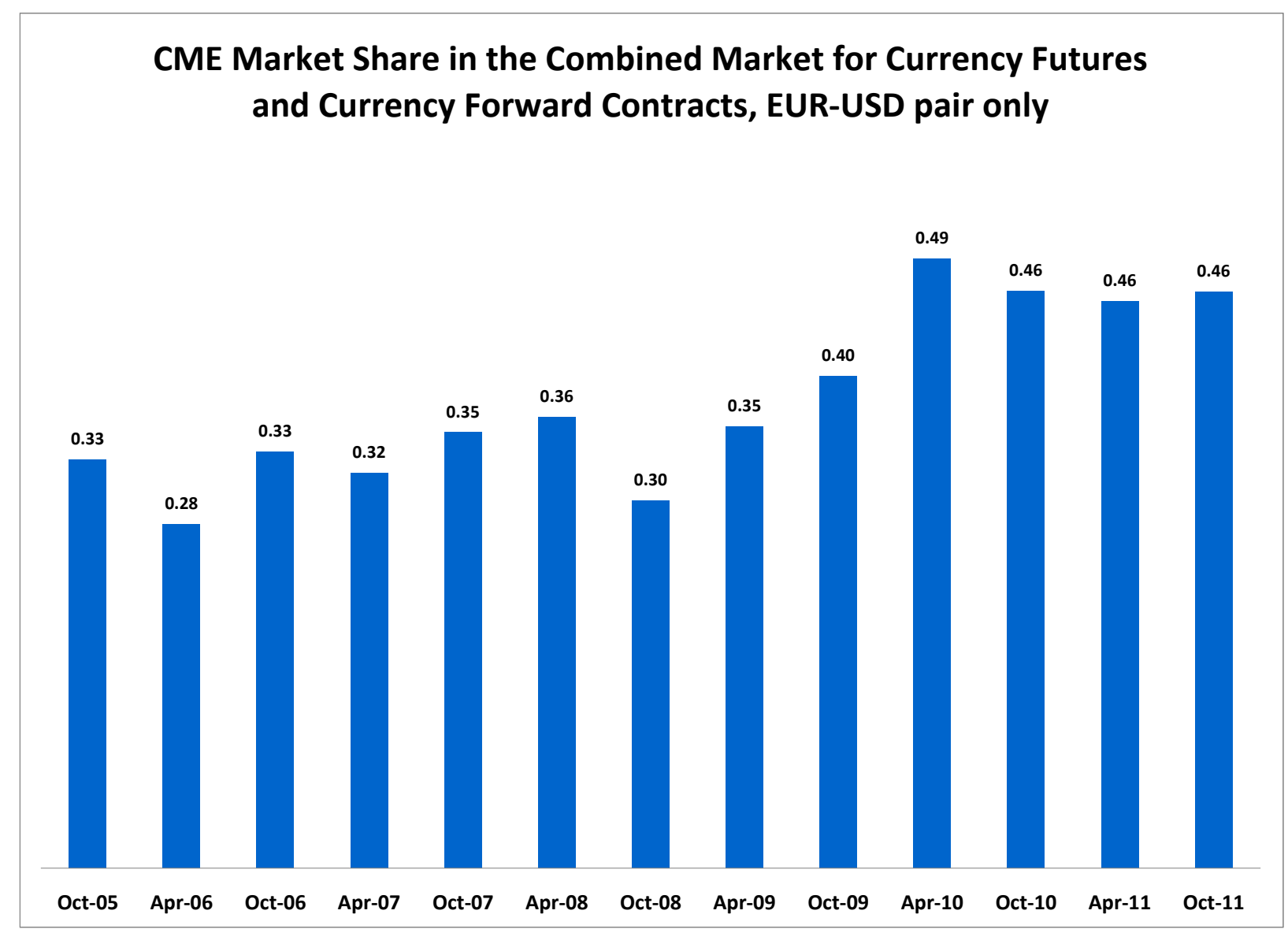

Note: Data on the aggregate volume of CME futures are from Bloomberg. Data on interbank outright forward contracts are from periodic surveys conducted by FX Committees in London, New York, Singapore, and Australia. 
Exhibit 6. EUR Interbank Forward Contracts and CME Futures on EUR, Daily Average Trading Volume in USD Millions

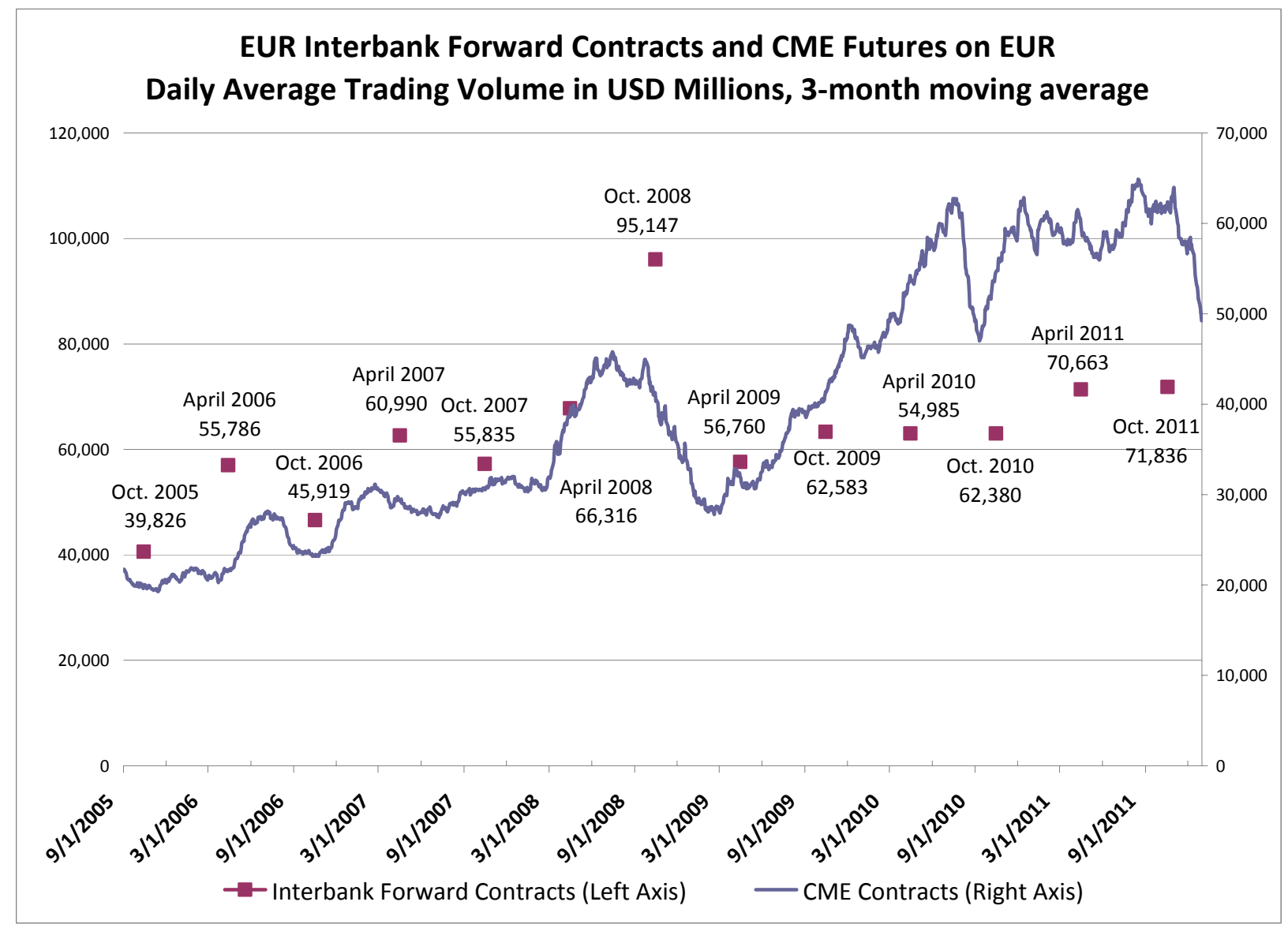

Note: $\quad$ Data on the aggregate volume of CME futures are from Bloomberg and include the period June 1, 2005 December 31, 2011. Data on interbank outright forward contracts are from periodic surveys conducted by FX Committees in London, New York, Singapore, and Australia. 
Exhibit 7. Daily Average Trading Volume for CME Currency Futures Contracts, Index: September 1, $2005=100$

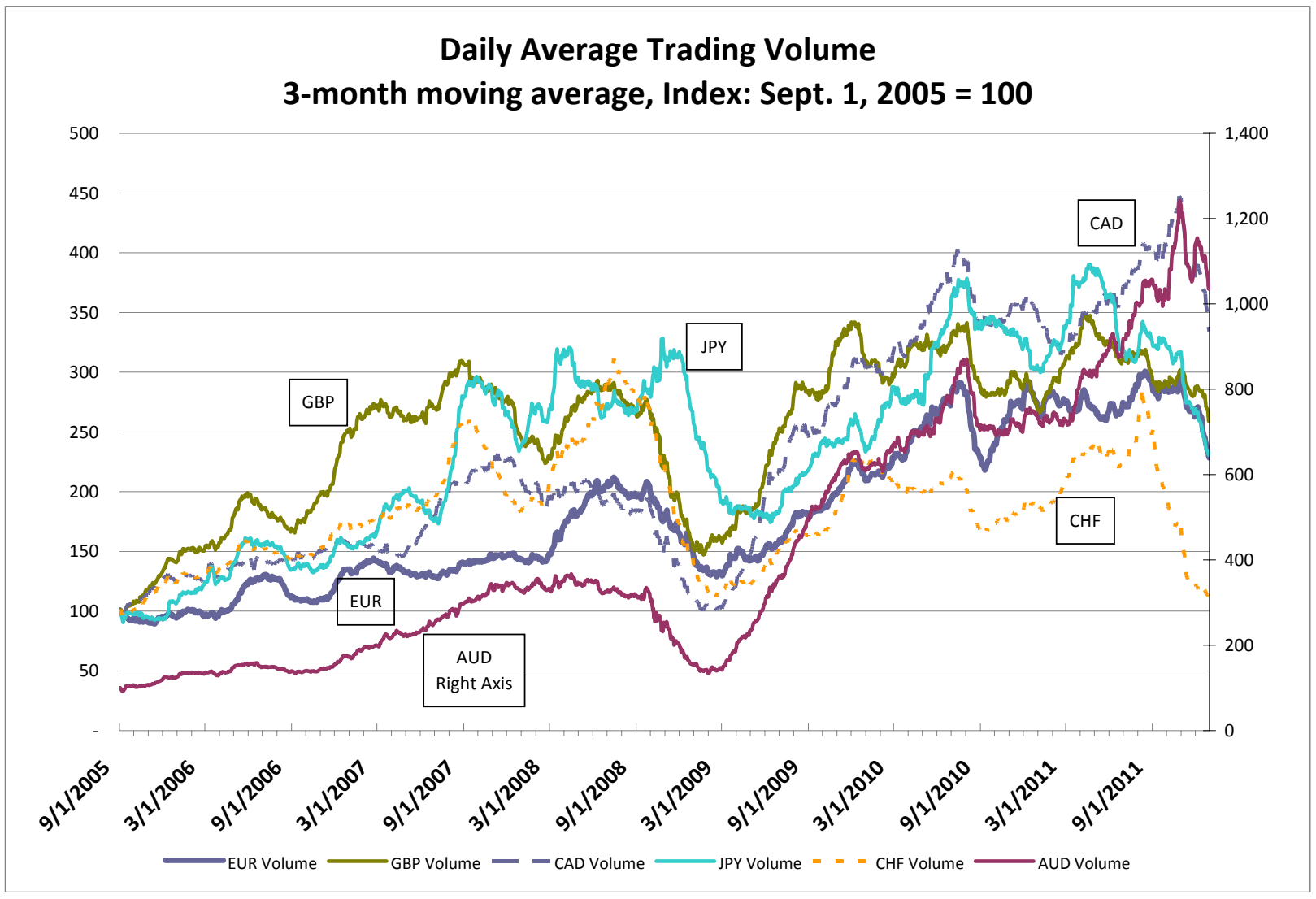

Note: Data on the aggregate volume of CME futures are from Bloomberg. The index is a 65-day moving average of the daily USD value of trading volume. 
Exhibit 8. Changes in the Daily Average CME Currency Futures Trading Volume and the USD Value of Contracts Traded

\begin{tabular}{|c|c|c|c|c|c|c|}
\hline & EUR & AUD & GBP & CAD & JPY & $\mathrm{CHF}$ \\
\hline \multicolumn{7}{|c|}{ Daily Average Number of Contracts Traded } \\
\hline 2005-Q3 & 134,376 & 18,235 & 37,218 & 31,494 & 50,096 & 29,487 \\
\hline 2011-Q4 & 301,344 & 132,027 & 101,770 & 82,979 & 80,837 & 25,071 \\
\hline Ratio & 2.24 & 7.24 & 2.73 & 2.63 & 1.61 & 0.85 \\
\hline \multicolumn{7}{|c|}{ Daily Average Value of Contracts, in USD millions } \\
\hline 2005-Q3 & 20,254 & 1,394 & 4,116 & 2,713 & 5,527 & 3,038 \\
\hline 2011-Q4 & 49,247 & 13,534 & 9,883 & 8,161 & 13,126 & 3,343 \\
\hline Ratio & 2.43 & 9.71 & 2.40 & 3.01 & 2.37 & 1.10 \\
\hline
\end{tabular}

Note: Data on the aggregate volume of CME futures are from Bloomberg. Daily spot exchange rates are from the Federal Reserve Board of Governors. 
Exhibit 9. CME Market Share in the Combined Market for Currency Futures and Currency Forward Contracts

\section{Percent Share of CME Trading Volume for October and April Survey Months}

\begin{tabular}{|r|c|l|l|l|l|l|l|l|}
\hline & $\begin{array}{c}\text { USD } \\
\text { Vs. }\end{array}$ & EUR & \multicolumn{1}{|c|}{ AUD } & GBP & CAD & JPY & CHF & JPY $^{*}$ \\
\hline October & 2005 & 0.33 & 0.16 & 0.18 & 0.06 & 0.21 & 0.33 & \\
\hline April & 2006 & 0.28 & 0.17 & 0.24 & 0.07 & 0.23 & 0.33 & 0.17 \\
\hline October & 2006 & 0.33 & 0.19 & 0.27 & 0.07 & 0.27 & 0.39 & \\
\hline April & 2007 & 0.32 & 0.24 & 0.29 & 0.07 & 0.31 & 0.42 & 0.24 \\
\hline October & 2007 & 0.35 & 0.27 & 0.30 & 0.08 & 0.46 & 0.41 & \\
\hline April & 2008 & 0.36 & 0.31 & 0.23 & 0.07 & 0.26 & 0.45 & 0.21 \\
\hline October & 2008 & 0.30 & 0.23 & 0.20 & 0.04 & 0.25 & 0.43 & \\
\hline April & 2009 & 0.35 & 0.24 & 0.23 & 0.05 & 0.19 & 0.36 & 0.16 \\
\hline October & 2009 & 0.40 & 0.34 & 0.31 & 0.09 & 0.20 & 0.44 & \\
\hline April & 2010 & 0.49 & 0.36 & 0.33 & 0.11 & 0.19 & 0.44 & 0.16 \\
\hline October & 2010 & 0.46 & 0.36 & 0.30 & 0.11 & 0.26 & 0.36 & \\
\hline April & 2011 & 0.46 & 0.40 & 0.33 & 0.09 & 0.29 & 0.40 & 0.24 \\
\hline October & 2011 & 0.46 & 0.42 & 0.28 & 0.10 & 0.25 & 0.40 & \\
\hline
\end{tabular}

Note: Data on the aggregate volume of CME futures are from Bloomberg. Data on interbank outright forward contracts are from periodic surveys conducted by FX Committees in London, New York, Singapore, Canada and Australia. Last column marked by * includes the annual survey in Tokyo. 